VIII. Ueber die Identitüt des sogenannten unreifen Bernsteins mit dem Krantzit; von Prof. H. Spirgatis in Königsberg.

Ich habe vor einiger Zeit darauf hingewiesen ${ }^{1}$ ), dafs der sogenannte unreife Bernstein, welcher bisweilen unter dem ostpreufsischen Bernstein gefunden wird, hinsichtlich seiner physikalischen Merkmale, sowie seines Verhaltens zu Lösungsmitteln eine gewisse Aehnlichkeit mit dem von Bergemann ${ }^{2}$ ) beschriebenen und untersuchten Krantzit zeige, der ursprünglich ebenfalls für eine Art Bernstein gehalten wurde.

Nachdem mir nunmehr der hiesige Geologe, Hr. Prof. Berendt, welchem ich bereits den unreifen Bernstein verdanke, auch eine Quantität Krantzit zur Verfügung gestellt und dadurch eine vergleichende Untersuchung beider Fossile ermőglicht hat, vermag ich dieselben für identisch zu erklären, insoweit annähernd gleiche physikalische und chemische Eigenschaften dazu berechtigen. Denn von absoluter Uebereinstimmung kann hier keine Rede seyn. Selbs Bruchstücke, welche von ein und demselben Exemplar des einen oder andern Minerals entnommen sind, differiren nicht unbeträchtlich bezüglich ihres specifischen Gewichts, ihres Aschengehalts, ihrer elementaren Zusammensetzung u. s. w., was ohne $\mathrm{Z}$ weifel daher kommt, dafs diese Fossile Gemenge mehrerer Verbindungen sind und ungleich vertheilte Quantităten von Verunreinigung enthalten. Die geringe Menge Material aber, welche mir zu Gebote stand, gestattete es nicht, eine Trennung in die näheren Bestandtheile zu versuchen. Der ganze Fund an unreifem Bernstein betrug ein etwa halbfaust grofses Sthck und der grölste Theil davon ist der geologischen Sammlung der

1) Sitzungsbericht der Königl. Bayrischen Akademie der Wissenschaften vom 6. Mai 1871.

2) Journal für praktische Chemie, Bd. 76, S. 65. 
hiesigen physikalisch-ökonomischen Gesellschaft einverleibt worden.

Der mir übergebene Krantzit besafs genau das Aussehen und die Consistenz des ostpreufsischen Harzes. Auch sein Verhalteu zu Lösungsmitteln, wie Weingeist, Aether, Terpentinöl, Chloroform, Schwefelkohlenstoff, Steinöl, Benzol, und zu Alkalien ist ganz dasselbe. Schwefelsäure verkohlt und löst ihn unter Braunfärbung wie den unreifen Bernstein.

Sein specifisches Gewicht fand ich bei einem Versuche zu 0,9822 , bei einem zweiten zu 0,9845 ; das des ostpreufsischen Harzes schwankte von 0,9344 bis $1,0244^{1}$ ).

Abweichend von Bergemann, der angiebt, dafs der Krantzit bei $288^{\circ}$ eine dünne Flüssigkeit bilde, begann der meinige, wie der unreife Bernstein, erst über $300^{\circ} \mathbf{z u}$ schmelzen. Beim Erhitzen an der Luft verbrennen beide Fossile mit leuchtender, ruf'sender Flamme unter Verbreitung eines eigenthümlichen Geruchs. Den Aschengehalt fand ich in dem ostpreufsischen Mineral von 0 bis 0,33 schwankend; im Krantzit vermochte ich, wie Bergeman n, keine Asche nachzuweisen und ebenso wenig Stickstoff, während der unreife Bernstein eine kleine, wohl zufällige Menge davon entbălt '). In beiden Harzen war keine Bernsteinsäure wahrzunehmen.

1) $0,1448 \mathrm{Grm}$. des lufttrockenen ostpreufsischen Harzes lieferten resp. nach Abzug der Asche . . . . $0,4567 \mathrm{CO}_{2}$ und $0,1424 \mathrm{H}_{2} \mathrm{O}$

2) 0,1357 Grm.

do. do. $0,3876 \mathrm{CO}_{2}$ und $0,1237 \mathrm{H}_{2} \mathrm{O}$

3) 0,1306 Grm. do. do. $0,3777 \mathrm{CO}_{2}$ und $0,1193 \mathrm{H}_{2} \mathrm{O}$.

1) Bergemann fand für den Krantzit ein specifisches Gewicht von 0,968.

2) Spirgatis, Sitzungsberichte der Königl. Bayrischen Akademie. 
1.

\section{C $86,02^{1}$ ) \\ II 10,93 \\ 77,89 \\ 10,13}

2.
3.

78,87

10,15

4) 0,1200 Grm. luftrockener Krantzit

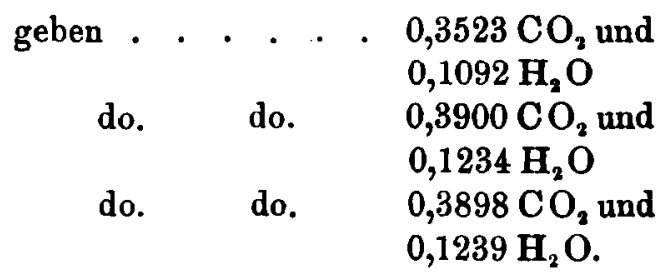

4.

5.

$\begin{array}{llll}\text { C } & 80,07 & 78,43 & \left.79,27^{2}\right) \\ \text { H } & 10,11 & 10,11 & 10,26\end{array}$

IX. Einige Versuche über die Umwandlung der lebendigen Kraft in Wärme; von Hrn. Volpicelli.

(Compt. rend. T. LXXIII, p. 492.)

$E_{s}$ ist veröffentlicht worden, dafs man eine TemperaturErniedrigung erhalte, wenn man Luft, die in einem zweckmäfsigen Behälter comprimirt worden, gegen eine Fläche der thermo-elektrischen Sãule ausströmen lasse.

1) Ich halte diese hohe, von den anderen beiden Analysen abweichende Kohlenstoffzahl für keinen Versuchsfehler, sondern ebenfalls für bedingt durch die ungleichartige Zusammensetzung des Fossils.

2) Diese Verbrennung hat fast genau dieselben Zablen ergeben, wolche von B ergeman erhalten wurden, als er das Material zum beginnenden Schmelzen erhitzte, das Schmelzproduct mit Weingeist auszog und nur den in Weingeist unlöslicben Rückstand verbrannte. Er erbielt:

79,25 Kohlenstoff und

10,41 Wasserstoff.

Poggendorff's Annal. Bd. CXLVI. 